Article

\title{
Effects of Human Activities on the Diversity of Waterbirds Wintering in a Shallow Lake of the Middle and Lower Yangtze River Floodplain, China
}

\author{
Xinjian Wang ${ }^{1,2}$, Jinyun Chen ${ }^{3}$ and Lizhi Zhou ${ }^{1,2, *}$ \\ 1 School of Resources and Environmental Engineering, Anhui University, 111 Jiulong Road, Hefei 230601, \\ China; wangxinjianemail@163.com \\ 2 Anhui Province Key Laboratory of Wetland Ecosystem Protection and Restoration, Anhui University, \\ 111 Jiulong Road, Hefei 230601, China \\ 3 College of Biological Engineering, Huainan Normal University, Dongshan West Road, Huainan 232038, \\ China; jinyunchen@163.com \\ * Correspondence: zhoulz@ahu.edu.cn
}

Received: 4 June 2020; Accepted: 31 July 2020; Published: 3 August 2020

\begin{abstract}
Human activity is the major factor driving the wetland degradation in shallow lakes. Human exploitation of lake wetlands alters the habitats of wintering waterbirds, and, in turn, waterbird diversity in the shallow lakes. In the present study, we surveyed species composition, abundance, and habitat characteristics of waterbirds in three types of wetland habitats (natural lakeside wetlands, paddy fields, and aquaculture ponds) at Caizi Lake, a shallow lake in the middle and lower Yangtze River during the wintering period, and investigated the effects of habitat change driven by human activity on the diversity of wintering waterbirds. There were significant differences in species composition and abundance among the three wetland habitats (natural lakeside wetlands, aquaculture ponds, and artificial paddy fields); however, there were no significant differences among the habitats with respect to the number of waterbirds. The numbers of overwintering waterbird species and waterbird individuals in aquaculture ponds and lakeside wetlands were significantly higher than the numbers in the paddy fields, indicating that wintering waterbirds prefer natural lake wetlands and aquaculture ponds. Principal component analysis of the three wetland habitat types revealed that factors influencing waterbird diversity include wetland area, vegetation cover, water level, and degree of human interference. Therefore, minimizing human interference and ensuring suitable habitats at specific periods could facilitate the maintenance of waterbird diversity.
\end{abstract}

Keywords: wintering waterbirds; community diversity; human activities; foraging habitat; Caizi Lake

\section{Introduction}

Waterbirds represent a key indicator taxon in wetland ecosystems [1] when considering how the quality of a wetland environment influences waterbird diversity. Wetland destruction or degradation has become a widespread global phenomenon due to increased human activity in the ecosystems. In recent years, an increase in the intensity of human activity, for example, through polder construction and aquaculture activities, has decreased the area of natural lake wetlands, which are converted into paddy fields, aquaculture ponds, and other artificial wetlands [2-4]. Such human activities alter habitats, which influences the number of wintering waterbirds and their distribution [5], foraging behavior [6], and interspecies competition [7]. Some studies have demonstrated that as natural lake wetland area decreases, artificial wetlands gradually become the substitute waterbird habitats $[8,9]$, which has some implications for the maintenance of the diversity of waterbird communities at specific periods [10-12], for example, based on suitable breeding and foraging sites in summer and winter, 
respectively [13-15]. However, numerous studies have demonstrated that waterbird communities are more diverse in natural wetlands when compared with artificial wetlands, and that artificial wetlands cannot replace the function of natural wetlands [16-18].

Shallow lake wetlands at the middle and lower Yangtze River floodplain are important wintering and stopover sites for the migratory waterbirds on the East Asian-Australasian flyway [18]. Every year, large numbers of waterbirds winter and stop at these sites, which are important aggregation sites for globally-migratory waterbirds $[19,20]$. The sites are also under the influence of human activities. The degradation and shrinking of many natural lake wetlands in the region and their transformation into artificial wetlands in the form of paddy fields and aquaculture ponds [19] has altered the habitats for waterbirds and could affect waterbird diversity.

To investigate the effects of human activities on lake-wintering waterbird diversity, we selected Caizi Lake at the Yangtze River floodplain in Anhui province as a study site and surveyed wintering waterbirds in three habitats (aquaculture ponds, paddy fields, and natural lakeside wetlands) to investigate the influence of human activity on the diversity of wintering waterbirds in inland lakes. The results of the present study could facilitate the management and sustainable utilization of lake wetlands.

\section{Materials and Methods}

\subsection{Study Area}

Caizi Lake is located at Anqing in southwestern Anhui province and has an area of $172.3 \mathrm{~km}^{2}$. The bottom of the lake has an elevation of $8.5 \mathrm{~m}$, a mean water depth of $1.67 \mathrm{~m}$, and a mean annual level difference of $8.5 \mathrm{~m}$. The climate of the region is a humid subtropical climate and the mean annual temperature is $16.5-16.7^{\circ} \mathrm{C}$. The mean temperature in December to February is less than $10.0^{\circ} \mathrm{C}$, and the lowest temperature occurs in January. The mean annual precipitation is $1291.33-1322.23 \mathrm{~mm}$ and precipitation is concentrated in May-June, which is the East Asian rainy season. The lake water level rises after a lag period and the high flow period fall in July-September, while dry periods fall in November-December and January-May in the following year.

The Caizi Lake system is a shallow river-connected lake. Due to soil erosion and sedimentation, a large area of the lake has transformed into a mudflat. Polders were constructed at the lake from the 1960s to 1970s to establish paddy fields to address a major shortage in arable land in the region [19]. At the end of last century, the growth of the crab aquaculture industry led to the transformation of large areas of lake wetlands into aquaculture ponds, which reduced the area of natural wetlands in the region considerably (Figure 1). Water level is a key factor influencing habitat exploitation by waterbirds [11,21] and water levels in natural wetlands at Caizi Lake shift based on river water level fluctuation. During the dry season, water level decreases to $10-50 \mathrm{~cm}$ and water level in paddy fields is around $0-10 \mathrm{~cm}$.

The water levels in aquaculture ponds are controlled manually; water level in aquaculture ponds is around $0-1.5 \mathrm{~m}$. However, the methods of exploitation of aquaculture ponds by local residents vary and fishing duration during winter can differ by 20-30 days. Therefore, there are no major water level trends. The water levels of some aquaculture ponds are maintained at high levels and the ponds do not dry up during winter. Vegetation is another key factor that influences habitat exploitation by waterbirds [22,23]. The natural wetlands at Caizi Lake have good vegetation cover and the major vegetation include emergent plants such as Persicaria orientalis and Phragmites communis, floating plants such as Lemna minor and Potamogeton malaianus, and submerged plants such as Ceratophyllum demersum, Vallisneria natans, and Potamogeton wrightii. Although the vegetation in aquaculture ponds is similar to the vegetation in natural lake regions, there is severe patch fragmentation and the distribution of vegetation in aquaculture ponds is uneven. Vegetation is severely degraded in aquaculture ponds that have been in use for many years. In addition, there is no vegetation cover in paddy fields and rice stubbles are left behind after harvesting, or wheat and rapeseed are cultivated. 


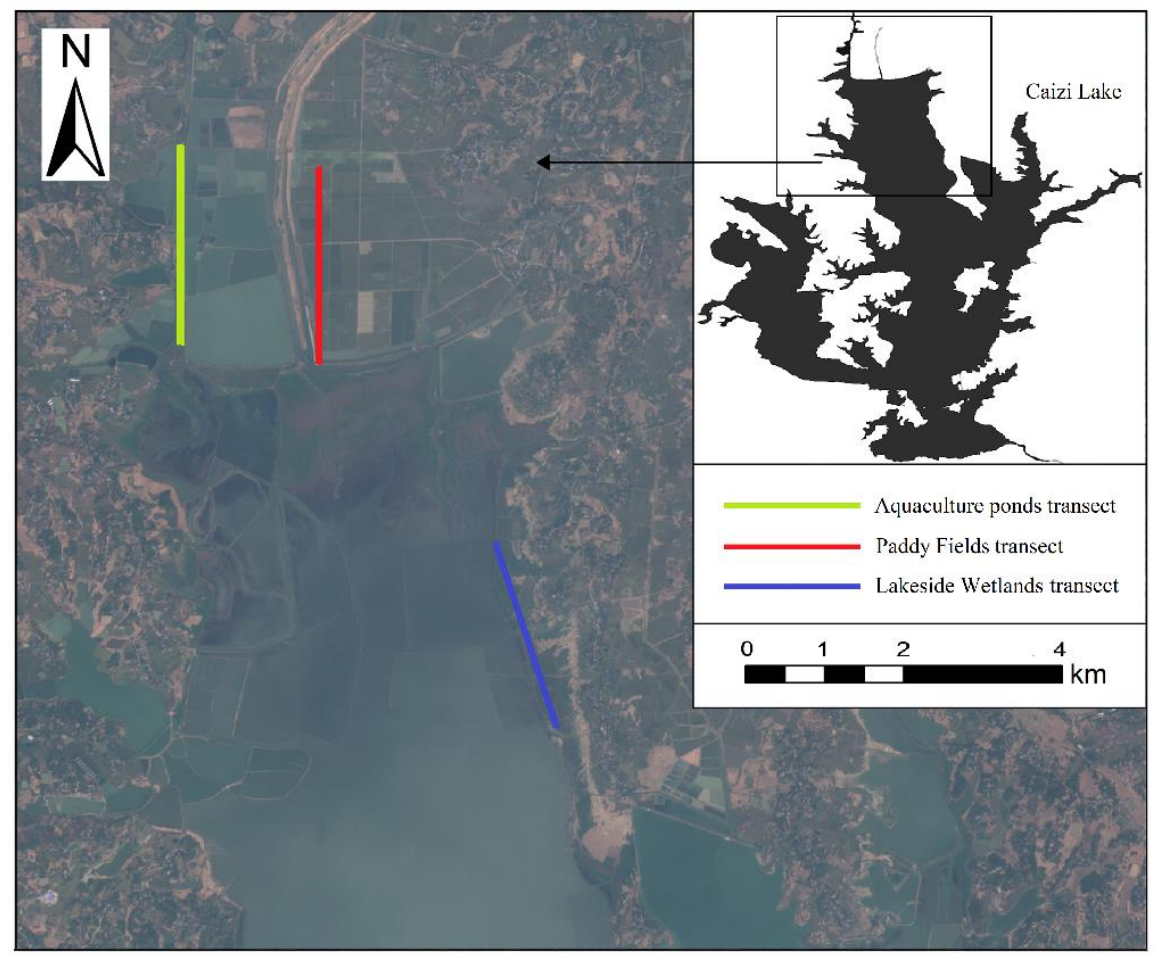

Figure 1. Location of the three survey transects at Caizi Lake.

\subsection{Study Methods}

\subsubsection{Waterbird Survey}

Every November, waterbirds begin to arrive at lakes in the middle and lower Yangtze River floodplain for overwintering and northward migration is resumed in March of the following year. The waterbird survey was conducted from November 2008 to March 2009 and from November 2009 to March 2010. A supplementary survey was conducted from November 2012 to March 2013. The survey route was parallel to the lake shore and three routes represent different wetland types: (A) aquaculture ponds, (B) paddy Fields, and (C) lakeside wetlands. The surveys were performed on foot and each transect had a length of $2.5 \mathrm{~km}$, width of $0.5 \mathrm{~km}$, and an area of $125 \mathrm{ha}$.

GPS was used to determine the positions of transects and a rangefinder (BUSHNELL,1500) was used to determine the areas of the habitats. A monocular $(16 / 52 \times)$ and binoculars $(8 \times)$ were used to identify the species and count the numbers of waterbirds in the survey sites. In regions with few waterbirds, direct enumeration was used to record the type and number of each bird species. In waterbird aggregation areas, "group number" was used for counting and 10, 20, or 50 were used as the enumeration units for counting bird numbers. Birds flying in the sky were not included in the total counts.

\subsubsection{Habitat Parameter Survey}

The habitat characteristics in different types of wetlands were investigated, including mean water depth, mudflat width and mudflat area ratio, water body area ratio, emergent vegetation area ratio, submerged vegetation area ratio, total vegetation cover, and human interference. As changes in vegetation cover in the entire study site during winter are not great, vegetation surveys were carried out in November 2008 and 2009 by using the Landsat-Thematic Mapper remote sensing satellite (Table 1). 
Table 1. The parameters of the habitat factors in three transects.

\begin{tabular}{|c|c|c|}
\hline Code & Habitat Factors & Explanation \\
\hline BMW (bare mudflat width) & Mudflat width (m) & Mudflat width in transect \\
\hline MA (mudflat area) & Mudflat area ratio (\%) & $\begin{array}{l}\text { Percentage of mudflat area over } \\
\text { total transect area }\end{array}$ \\
\hline WA (water area) & Water body area ratio (\%) & $\begin{array}{l}\text { Ratio of water body area to } \\
\text { transect area }\end{array}$ \\
\hline EPC (emerged plants coverage rate) & Emergent vegetation area ratio (\%) & $\begin{array}{l}\text { Percentage of area covered by } \\
\text { emergent vegetation }\end{array}$ \\
\hline SPC (submerged plants coverage rate) & Submerged vegetation area ratio (\%) & $\begin{array}{l}\text { Percentage of area covered by } \\
\text { submerged vegetation }\end{array}$ \\
\hline TPC (total plants coverage rate) & Total vegetation cover $(\%)$ & Vegetation cover of the transect \\
\hline AWD (average water depth) & Water depth $(\mathrm{cm})$ & Water depth in transect \\
\hline $\begin{array}{l}\text { DHA (disturbners of human and } \\
\text { animals) }\end{array}$ & Human interference & Number of people and livestock \\
\hline
\end{tabular}

Remote sensing satellite images taken on 8 November 2008 were used to analyze auxiliary vegetation, water level, and human interference, while other factors were investigated during water level surveys. The bird checklist of the survey mainly refers to IOC World Bird List (v10.1) [24].

\subsubsection{Data Analysis}

The number of birds in a transect was converted into the number of individuals per unit area according to the length of the transect and the area under observation. Populations that exceeded $10 \%$ of the total number of waterbirds were defined as dominant populations, populations that consisted of $1-10 \%$ of the total number of waterbirds were defined as ordinary populations, and those that were less than $1 \%$ were considered rare populations. During the survey periods in winter, there was no major change in the landscape environment of the study site; therefore, data in the same transect were considered replicate statistics to minimize random errors. Waterbird diversity is a key indicator of habitat quality. The diversity was calculated using the Shannon-Wiener index $\left(H^{\prime}\right)$ [25], evenness was calculated using the Pielou's evenness index(J) [26], and dominance was calculated by using the Simpson index $(C)$ [25]. The indices were used to evaluate differences in species diversity under different types of wetlands. In the equation, $S$ is the number of waterbird species, $P_{i}$ is the ratio of the number of bird species in wetland $i$ to the total number of waterbird species in all three wetland types, and $H^{\prime}{ }_{\max }$ is $\ln S$, which is maximum diversity:

$$
\begin{gathered}
H \prime=-\sum_{\mathrm{i}=1}^{\mathrm{s}} P \mathrm{i} \cdot \ln P \mathrm{i} \\
J=H^{\prime} / H^{\prime} \max \\
C=1-\sum_{i=1}^{S} P i^{2}
\end{gathered}
$$

The data of the number of waterbirds, number of waterbird species, and the number of bird for each species among lakeside wetlands, aquaculture ponds, and paddy fields were tested for normality by using the one-sample Kolmogorov-Smirnov test. If the data followed a normal distribution we analyzed them in a one-way ANOVA; if the data did not follow a normal distribution we used the non-parametric of the Kruskal-Wallis $\mathrm{H}$ test and the Mann-Whitney $\mathrm{U}$ test. The test results showed that the data was normally distributed. Habitat quality is also a key factor influencing the distribution of waterbirds in wintering sites. To evaluate the habitat factors influencing waterbird diversity characteristics at different wetland types, principal component analysis (PCA) was used to analyze factors influencing waterbird populations in aquaculture ponds, lakeside wetlands, and paddy fields. A significance level of $0.05(p)$ was used for all statistical tests, with means stated as mean \pm SD. IBM SPSS Statistics (IBM Corp., Armonk, NY, USA) (Version 17.0) was used for statistical analysis. 


\section{Results}

\subsection{Waterbird Species and Number in Different Wetlands}

During the study period, 39 waterbird species and 48,094 individuals were recorded, which belonged to 7 orders (Tables 2 and 3). There were 14 species (35.90\%) and 36,434 individuals (76.76\%) from the order Anseriformes, and 13 species (33.33\%) and 3,972 individuals(8.26\%) from the order Charadriiformes. There were 4 species (10.26\%) and 5,201 individuals (10.81\%) from the order Pelecaniformes, while the number of species and individuals in 4 orders (Podicipediformes, Suliformes, Ciconiiformes, and Gruiformes) did not exceed $10 \%$ of the total number.

In the three types of habitat, aquaculture ponds had the most waterbird species (30 species), followed by lakeside wetlands ( 27 species), and paddy fields ( 13 species), and the numbers of waterbird individuals in the three habitats accounted for $76.92 \%, 69.23 \%$, and $33.33 \%$ of the total number of waterbird species, respectively. There were significant differences in species composition among the overwintering waterbird communities $(n=24, \mathrm{~F}=4.17, p<0.05)$, and the numbers of overwintering waterbird species in aquaculture ponds and lakeside wetlands were significantly higher than the numbers in the paddy fields.

There were 27,474, 9681, and 10,935 waterbird individuals in the aquaculture ponds, lakeside wetlands, and paddy fields, respectively, accounting for $57.13 \%, 22.74 \%$, and $20.13 \%$ of the total number of waterbirds counted, respectively. Based on the number of waterbird individuals, aquaculture ponds are important habitats for overwintering waterbirds; however, the differences in the number of wintering waterbirds among the three habitats were not significant $(n=24, \mathrm{~F}=1.83, p>0.05)$.

The dominant species in the aquaculture ponds were Cygnus columbianus and Anser cygnoides, which were $1484.50 \pm 2287.95$ and $1307.50 \pm 1305.98$ individuals, respectively. However, the dominant species in paddy fields were Ardea cinerea, Ardea alba, and A. cygnoides, with 123.63 $\pm 106.13,113.75 \pm$ 106.54, and $919.00 \pm 1089.63$ individuals, respectively. The dominant species in the lakeside wetlands were A. cygnoides, Anser fabalis, and Calidris alpina, with 496.25 $\pm 647.72,264.00 \pm 693.7$, and $708.50 \pm$ 1746.2 individuals, respectively. There were significant differences in species composition among the overwintering waterbird communities $(n=24, \mathrm{~F}=4.17, p<0.05)$, and the numbers of overwintering waterbird species in aquaculture ponds and lakeside wetlands were significantly higher than the numbers in the paddy fields.

For each order, the number of individuals per species did not differ significantly between habitats. With the exception Charadriiform, the number species per order did not differ significantly between habitats.

There were 2 waterbird species from the order Podicipediformes, representing 198 individuals, and both species were observed in aquaculture ponds and lakeside wetlands, with 155 and 43 individuals, respectively (Table 3). Non-parametric tests results revealed that the difference in the number of Podicipediformes birds between the two habitats was not significant $(\chi 2=0.285, d f=2, p=0.867$ ). There was 1 species and 2 individuals from the order Suliformes, namely, Phalacrocorax carbo, and it was observed only in aquaculture ponds. There were 4 species and 5201 individuals from the order Pelecaniformes, with 3 species and 1958 individuals, 4 species and 1900 individuals, and 2 species and 1343 individuals observed in the aquaculture ponds, paddy fields, and lakeside wetlands, respectively $\left(\chi^{2}=3.378, d f=2, p=0.19\right)$. There were 14 species and 36,434 individuals from the order Anseriformes, out of which 10 species and 22,649 individuals, 5 species and 7065 individuals, and 9 species and 6720 individuals were observed in the aquaculture ponds, paddy fields, and lakeside wetlands, respectively $\left(\chi^{2}=2.28, d f=2, p=0.32\right)$. 
Table 2. Species and individuals of waterbirds in different habitat types.

\begin{tabular}{|c|c|c|c|c|c|c|c|c|c|}
\hline \multicolumn{2}{|c|}{ Order } & \multicolumn{2}{|c|}{ Aquaculture Ponds } & \multicolumn{2}{|c|}{ Paddy Fields } & \multicolumn{2}{|c|}{ Lakeside Wetlands } & \multicolumn{2}{|c|}{ Total } \\
\hline & & Richness & Percentage & Richness & Percentage & Richness & Percentage & Richness & Percentage \\
\hline \multirow{8}{*}{$\begin{array}{l}\text { Species } \\
\text { Number }\end{array}$} & Podicipediformes & 2 & 6.67 & 0 & 0.00 & 2 & 7.41 & 2 & 5.13 \\
\hline & Suliformes & 1 & 3.33 & 0 & 0.00 & 0 & 0.00 & 1 & 2.56 \\
\hline & Pelecaniformes & 3 & 10.00 & 4 & 30.77 & 2 & 7.41 & 4 & 10.26 \\
\hline & Ciconiiformes & 1 & 3.33 & 2 & 15.38 & 1 & 3.70 & 2 & 5.13 \\
\hline & Anseriformes & 10 & 33.33 & 5 & 38.46 & 9 & 33.33 & 14 & 35.90 \\
\hline & Gruiformes & 3 & 10.00 & 1 & 7.69 & 2 & 7.41 & 3 & 7.69 \\
\hline & Charadriiformes & 10 & 33.33 & 4 & 30.77 & $\overline{9}$ & 33.33 & 13 & 33.33 \\
\hline & Total & 30 & 76.92 & 13 & 33.33 & 27 & 69.23 & 39 & 100 \\
\hline \multirow{8}{*}{$\begin{array}{l}\text { Individuals } \\
\text { Number }\end{array}$} & Podicipediformes & 155 & 0.56 & 0 & 0.00 & 43 & 0.39 & 198 & 0.41 \\
\hline & Suliformes & 2 & 0.01 & 0 & 0.00 & 0 & 0.00 & 2 & 0.00 \\
\hline & Pelecaniformes & 1958 & 7.13 & 1900 & 19.63 & 1343 & 12.28 & 5201 & 10.81 \\
\hline & Ciconiiformes & 453 & 1.65 & 118 & 1.22 & 94 & 0.86 & 666 & 1.38 \\
\hline & Anseriformes & 22,649 & 82.43 & 7065 & 72.98 & 6720 & 61.45 & 36,434 & 75.76 \\
\hline & Gruiformes & 439 & 1.60 & 520 & 5.37 & 662 & 6.05 & 1621 & 3.37 \\
\hline & Charadriiformes & 1821 & 6.63 & 78 & 0.81 & 2073 & 18.96 & 3972 & 8.26 \\
\hline & Total & 27,477 & 57.13 & 9681 & 20.13 & 10,935 & 22.74 & 48,094 & 100 \\
\hline
\end{tabular}


Table 3. Species richness of waterbirds in different habitats.

\begin{tabular}{|c|c|c|c|c|c|c|c|}
\hline Order & Species & $\begin{array}{l}\text { Aquaculture } \\
\text { Ponds }\end{array}$ & $\begin{array}{c}\text { Percentage of } \\
\text { Total Community }\end{array}$ & Paddy Fields & $\begin{array}{c}\text { Percentage of } \\
\text { Total Community }\end{array}$ & $\begin{array}{l}\text { Lakeside } \\
\text { Wetlands }\end{array}$ & $\begin{array}{c}\text { Percentage of } \\
\text { Total Community }\end{array}$ \\
\hline \multirow{2}{*}{ Podicipediformes } & Tachybaptus ruficollis & $15.63 \pm 17.44$ & + & - & + & $7.38 \pm 14.21$ & + \\
\hline & Podiceps cristatus & $1.25 \pm 2.12$ & + & - & + & $0.25 \pm 0.71 *$ & + \\
\hline Suliformes & Phalacrocorax carbo & $0.25 \pm 0.71$ & + & - & + & - & + \\
\hline \multirow{4}{*}{ Pelecaniformes } & Ardea cinerea & $83.38 \pm 76.33$ & ++ & $123.63 \pm 106.13$ & +++ & $86.25 \pm 101.59$ & ++ \\
\hline & Ardea alba & $72.63 \pm 85.74$ & ++ & $113.75 \pm 106.54$ & +++ & $51.38 \pm 62.62$ & ++ \\
\hline & Ardea intermedia & - & + & - & + & $1.25 \pm 3.54$ & + \\
\hline & Platalea leucorodia & $88.75 \pm 132.28$ & ++ & - & + & $15.00 \pm 42.43$ & ++ \\
\hline \multirow[t]{2}{*}{ Ciconiiformes } & Ciconia nigra & - & + & $0.25 \pm 0.71$ & + & - & + \\
\hline & Ciconia boyciana & $56.63 \pm 84.15$ & + & $14.25 \pm 27.89$ & ++ & $9.25 \pm 9.13$ & + \\
\hline \multirow[t]{14}{*}{ Anseriformes } & Cygnus columbianus & $1484.50 \pm 2287.95$ & +++ & - & + & $25.00 \pm 70.71 *$ & ++ \\
\hline & Anser cygnoides & $1307.50 \pm 1305.98$ & +++ & $919.00 \pm 1089.63$ & +++ & $496.25 \pm 647.72$ & +++ \\
\hline & Anser fabalis & $5.75 \pm 8.10$ & + & - & + & $264.00 \pm 693.76$ & +++ \\
\hline & Anser albifrons & - & + & $0.25 \pm 0.71$ & + & - & + \\
\hline & Anser erythropus & - & + & $0.25 \pm 0.71$ & + & - & + \\
\hline & Anser anser & $0.50 \pm 1.41$ & + & $0.50 \pm 1.41$ & + & & + \\
\hline & Todorna ferruginea & $4.63 \pm 5.50$ & + & $25.63 \pm 31.79$ & ++ & $76.00 \pm 68.59 *$ & ++ \\
\hline & Mareca penelope & - & + & $1.00 \pm 2.83$ & + & $2.75 \pm 7.01$ & + \\
\hline & Mareca falcata & $2.25 \pm 3.11$ & + & - & + & - & + \\
\hline & Anas crecca & $7.88 \pm 22.27$ & + & & + & $2- \pm 56.57$ & ++ \\
\hline & Anas platyrhynchos & $2.25 \pm 6.36$ & + & - & + & $7.50 \pm 11.05$ & + \\
\hline & Anas poecilorhyncha & $14.75 \pm 22.72$ & + & - & + & $25.75 \pm 52.93$ & ++ \\
\hline & Anas acuta & $1.13 \pm 3.18$ & + & $1.88 \pm 5.30$ & + & - & + \\
\hline & Spatula querquedula & - & + & - & + & $0.75 \pm 2.12$ & + \\
\hline \multirow[t]{3}{*}{ Gruiformes } & Leucogeranus leucogeranus & $0.25 \pm 0.71$ & + & - & + & - & + \\
\hline & Grus monacha & $52.38 \pm 78.97$ & ++ & $115.50 \pm 119.82$ & ++ & $100.50 \pm 60.11$ & ++ \\
\hline & Paragallinula angulata & $4.50 \pm 11.56$ & + & - & + & $2.75 \pm 7.78$ & + \\
\hline \multirow[t]{13}{*}{ Charadriiformes } & Recurvirostra avosetta & $10.38 \pm 15.00$ & + & - & + & $1.50 \pm 2.78$ & + \\
\hline & Charadrius dubius & $3.25 \pm 9.19$ & + & $7.00 \pm 14.74$ & + & $3.00 \pm 6.93$ & + \\
\hline & Charadris alexandrinus & - & + & $0.38 \pm 1.06$ & + & - & + \\
\hline & Gallinago gallinago & $0.38 \pm 1.06$ & + & - & + & $0.13 \pm 0.35$ & + \\
\hline & Limosa limosa & $15.00 \pm 424.26$ & ++ & - & + & - & + \\
\hline & Numenius arquata & - & + & - & + & $0.25 \pm 0.71$ & + \\
\hline & Tringa erythropus & $5.88 \pm 11.22$ & + & $1.88 \pm 4.91$ & + & $3.88 \pm 6.69$ & + \\
\hline & Tringa totanus & - & + & - & + & $3.75 \pm 10.61$ & + \\
\hline & Tringa nebularia & $7.25 \pm 13.42$ & + & $0.63 \pm 1.41$ & + & $16.00 \pm 42.07$ & ++ \\
\hline & Tringa ochropus & $1.13 \pm 3.18$ & + & - & + & - & + \\
\hline & Calidris alpina & $45.63 \pm 72.28$ & ++ & - & + & $708.50 \pm 1746.2$ & +++ \\
\hline & Larus argentatus & $5.75 \pm 7.05$ & + & - & + & $3.00 \pm 2.88$ & + \\
\hline & Chroicocephalus ridibundus & $1.88 \pm 5.30$ & + & - & + & - & + \\
\hline
\end{tabular}

populations; " ++ ", ordinary populations; and " +++ ", rare populations. 
There were differences in the number of Anseriform birds among habitats, although the differences were not significant. There were 3 species and 1621 individuals from the order Gruiformes, out of which 3 species and 439 individuals, 1 species and 520 individuals, and 2 species and 662 individuals were observed in the aquaculture ponds, paddy fields, and lakeside wetlands, respectively. Similarly, there were differences in the number of Gruiform birds between habitats although the differences were not significant $\left(\chi^{2}=1.36, d f=2, p=0.51\right)$. In addition, there were 13 species and 3972 individuals from the order Charadriiformes, out of which 10 species and 1821 individuals, 4 species and 78 individuals, and 9 species and 2073 individuals were observed in the aquaculture ponds, paddy fields, and lakeside wetlands, respectively. There were differences in the number of Charadriiform birds among habitats, although there were no significant differences $\left(x^{2}=7.49, d f=2, p=0.02\right)$.

\subsection{Wintering Waterbird Diversity in Different Types of Wetlands}

Wintering waterbird data obtained during the survey were used for estimating species diversity, community evenness, and community dominance indices in the three habitats. With regards to the diversity index, waterbird species diversity in natural lakeside wetlands was significantly higher than the species diversity in paddy fields, with species diversity in aquaculture ponds being moderate, with no significant difference in waterbird species diversity between aquaculture ponds and paddy fields. The evenness index of waterbird communities in natural lakeside wetlands was the highest, followed by paddy fields, and aquaculture ponds, although the differences in evenness indices among the three habitats were not significant. The dominance by a single species was the lowest in the natural lakeside wetlands, with significant differences between the natural lakeside wetland and the aquaculture ponds and paddy fields $(n=24, \mathrm{~F}=6.23, p=0.026$ ) (Table 4$)$.

Table 4. Species diversity of waterbirds in different types of wetlands.

\begin{tabular}{cccc}
\hline Wetland Type & Shannon-Wiener Index $\left(\boldsymbol{H}^{\prime}\right)$ & Pielou Index $(\boldsymbol{J})$ & Simpson Index $(\boldsymbol{C})$ \\
\hline Lakeside wetland & $1.50 \pm 0.31 \mathrm{a}$ & $0.44 \pm 0.13 \mathrm{a}$ & $0.35 \pm 0.13 \mathrm{a}$ \\
Aquaculture ponds & $1.02 \pm 0.60 \mathrm{ab}$ & $0.29 \pm 0.16 \mathrm{a}$ & $0.55 \pm 0.26 \mathrm{~b}$ \\
Paddy fields & $0.90 \pm 0.42 \mathrm{~b}$ & $0.38 \pm 0.14 \mathrm{a}$ & $0.55 \pm 0.21 \mathrm{~b}$ \\
\hline
\end{tabular}

The values are mean \pm standard deviation; different letters in the same column mean that there is a significant difference in that index $(p<0.05)$.

The proportions of different waterbird taxa varied within habitats. In the wintering waterbird communities in the middle and lower Yangtze River floodplain, Anseriformes was the major ecological taxon. There were significant differences in the waterbird numbers of Anseriformes among the three wetland types $(n=24, \mathrm{~F}=4.65, p=0.02)$. Further multiple comparisons revealed that the difference in Anseriformes distribution between natural wetlands and aquaculture ponds was not significant $(p=$ $0.87)$, while there was a significant difference between paddy fields and natural lakes $(p=0.01)$, and between paddy fields and aquaculture ponds $(p=0.02)$.

\subsection{Environmental Factors Influencing Waterbird Diversity}

Based on the PCA results for the aquaculture ponds, the first two principal components explained $77.54 \%$ of the variance. The eigenvalue of the first principal component was 4.16 and it explained $52.04 \%$ of the variation. The factors with the highest load were vegetation cover and mudflat width. The eigenvalue of the second principal component was 2.040, and it explained $25.50 \%$ of the variation. The factors with the highest loads were human interference, water body area ratio, and mudflat area ratio (Tables 5 and 6). 
Table 5. Total variance explained of principal components in different habitats.

\begin{tabular}{|c|c|c|c|c|c|c|c|c|c|}
\hline \multirow{2}{*}{$\begin{array}{l}\text { Principal } \\
\text { Component }\end{array}$} & \multicolumn{3}{|c|}{ Aquaculture Ponds } & \multicolumn{3}{|c|}{ Paddy Fields } & \multicolumn{3}{|c|}{ Lakeside Wetlands } \\
\hline & Eigenvalue & $\begin{array}{c}\text { Contributing } \\
\text { Rate }\end{array}$ & $\begin{array}{c}\text { Cumulative } \\
\text { Contributing Rate }\end{array}$ & Eigenvalue & $\begin{array}{c}\text { Contributing } \\
\text { Rate }\end{array}$ & $\begin{array}{c}\text { Cumulative } \\
\text { Contributing Rate }\end{array}$ & Eigenvalue & $\begin{array}{c}\text { Contributing } \\
\text { Rate }\end{array}$ & $\begin{array}{c}\text { Cumulative } \\
\text { Contributing Rate }\end{array}$ \\
\hline 1 & 4.163 & 52.040 & 52.040 & 3.677 & 45.964 & 45.964 & 3.341 & 41.768 & 41.768 \\
\hline 2 & 2.040 & 25.500 & 77.541 & 1.766 & 22.070 & 68.034 & 2.034 & 25.424 & 67.192 \\
\hline 3 & 0.865 & 10.814 & 88.355 & 1.353 & 16.912 & 84.946 & 1.406 & 17.578 & 84.770 \\
\hline
\end{tabular}

Table 6. Principal components of habitat factors in different habitats.

\begin{tabular}{ccccccccc}
\hline \multirow{2}{*}{ Variable } & \multicolumn{2}{c}{ Aquaculture Ponds } & \multicolumn{3}{c}{ Paddy Fields } & \multicolumn{3}{c}{ Lakeside Wetlands } \\
\cline { 2 - 8 } & $\mathbf{1}$ & $\mathbf{2}$ & $\mathbf{1}$ & $\mathbf{2}$ & $\mathbf{3}$ & $\mathbf{1}$ & $\mathbf{2}$ & $\mathbf{3}$ \\
\hline BMW & 0.857 & -0.115 & 0.786 & -0.337 & -0.510 & 0.101 & 0.850 & 0.113 \\
MA & -0.743 & -0.606 & -0.859 & 0.166 & 0.436 & -0.832 & 0.486 & -0.080 \\
WA & 0.743 & 0.606 & 0.017 & 0.879 & -0.094 & 0.832 & -0.486 & 0.080 \\
EPC & 0.604 & 0.395 & 0.733 & 0.260 & -0.174 & -0.869 & 0.041 & -0.441 \\
SPC & 0.755 & -0.386 & 0.823 & 0.106 & 0.477 & 0.902 & 0.343 & -0.114 \\
TPC & 0.931 & -0.170 & 0.855 & 0.124 & 0.444 & 0.789 & 0.461 & -0.339 \\
AWD & -0.666 & 0.541 & -0.144 & 0.671 & -0.644 & -0.266 & -0.065 & 0.859 \\
DHA & -0.282 & -0.816 & 0.140 & 0.758 & 0.276 & 0.139 & 0.485 & 0.517 \\
\hline
\end{tabular}


According to the PCA analysis results for paddy fields, the first three principal components explained $84.95 \%$ of the variation. The eigenvalue of the first principal component was 3.68 and it explained $45.95 \%$ of the variation. The factors with the highest load were vegetation cover and mudflat area. The eigenvalue of the second principal component was 1.77 and it explained $22.07 \%$ of the variation. The factors with the highest load were water body area ratio and human interference. The eigenvalue of the third principal component was 1.353 and it explained $16.91 \%$ of the variation. The factor with the highest load was mean water depth.

In the PCA results for lakeside wetlands, the habitat factors with highest loads in the first principal component were submerged vegetation area ratio and emergent vegetation area ratio, while the factor with the highest load in the second principal component was mudflat width. The habitat factor with the highest load in the third principal component was mean water depth.

\section{Discussion}

\subsection{Spatial Distribution of Overwintering Waterbirds}

Species abundance and the number of individuals in a community are key indicators of waterbird diversity [27-29]. The study results showed that artificial conversion of lakeside wetlands into aquaculture ponds and paddy fields influenced the spatial distribution of wintering waterbirds. Waterbird diversity in natural lakeside wetlands was significantly greater than the diversity in paddy fields. Aquaculture ponds are another form of converted land and the waterbird diversity in the ponds was lower than in natural lakeside wetlands. With regard to the dominance index, large numbers of Anatidae aggregated in aquaculture ponds and paddy fields. Therefore, there were more overwintering waterbird species in natural lakeside wetlands; however, the number of individuals of each species were low and communities were even. In aquaculture ponds and paddy fields, the number of species was larger, and the dominance indices were higher. Natural lakeside wetlands have more microhabitats than artificial wetlands, in addition to higher habitat heterogeneity, and can accommodate more waterbird species [30,31]. Therefore, the waterbird conservation value of natural wetlands in inland lakes is higher than the value of aquaculture ponds and artificial paddy fields. In the present study, the differences in evenness in waterbird communities among the three habitats was low, and was the lowest in aquaculture ponds, which may be due to more uneven distribution of suitable food resources for waterbirds in aquaculture ponds when compared with the other two types of wetland habitats.

\subsection{Factors Influencing Community Structure of Waterbirds}

There were no significant differences in number of wintering waterbird individuals among the three types of wetland ecosystems $(p>0.05)$. However, the number of wintering waterbird species decreased significantly in paddy fields with low water levels $(p<0.05)$. Similarly, the distribution of Anatidae waterbirds in the middle and lower Yangtze River floodplain indicated that these birds preferred wetlands, and that natural lakeside wetlands and aquaculture ponds were major wintering sites for most Anatidae species, while shallow paddy fields were only suitable for foraging by a few Anatidae individuals. The results suggest that artificial wetlands can become a temporary substitute habitats for wintering waterbirds for relatively short periods. As socioeconomic development occurs, and populations increase, more natural wetlands are converted into artificial hydrologically-controlled habitats [32,33], which, in turn, changes vegetation quality [34]. As substitute habitats for natural wetlands, researchers are increasingly paying attention to artificial wetlands in waterbird conservation efforts, as they are potential substitute habitats for natural wetlands [35,36]. Some studies have reported that aquaculture ponds and flooded paddy fields are critical habitats for wintering waterbirds $[37,38]$. In the present study, the major environmental factors influencing waterbird diversity in natural lakeside wetlands include submerged vegetation ratio, emergent vegetation ratio, and mean water depth, 
showing that food and food availability are key factors influencing the community composition of wintering waterbirds in lakeside wetlands.

In the present study, there were no significant differences in the number of wintering waterbird species between the aquaculture ponds and the natural lakeside wetlands $(p>0.05)$, and the habitat factors with considerable effects on aquaculture ponds and paddy fields were vegetation status, mudflat width, and water level. At later stages of wintering, as precipitation increases and the water level of the Yangtze River increases, lake water level increases and aquaculture ponds and flooded paddy fields around the lake become major substitute overwintering habitats for migratory birds.

Different waterbird taxa prefer different wetland habitats [39]. In lake-wintering waterbird communities in the middle and lower Yangtze River floodplain, the dominant species are Anatidae waterbirds, which prefer lakeside wetlands with large mudflat areas and aquaculture ponds, and they have a low preference for paddy fields, largely because Anatidae waterbirds feed mainly on rhizome shoots in vegetation and their foraging behavior is influenced by water depth and matrix [31]. A study reported that wintering C. columbianus distribution in lakes in the middle and lower Yangtze River floodplain was affected mainly by water body surface area and water depth [2,38-42]. Some Anatidae waterbirds such as $A$. fabalis can tolerate considerable water level fluctuations and forage in paddy fields with relatively hard matrices. Therefore, flooded paddy fields in the lower and middle reaches of the Yangtze River also represent essential supplemental foraging sites for overwintering birds [2,42].

\subsection{Shallow Lake Management}

A study showed that compared with artificial wetlands (aquaculture ponds), waterbirds prefer natural wetlands [16]. However, the abundance of waterbird communities in aquaculture ponds during the overwintering period exceeded the abundance in natural wetlands [16]. In some regions, large endangered waterbirds are only found in natural wetlands. Therefore, the function of natural wetlands in waterbird conservation cannot be replaced by artificial wetlands [8]. However, according to the results of the present study, waterbirds such as Grus monacha can forage in natural wetlands, aquaculture ponds, and paddy fields while wintering in the middle and lower Yangtze River floodplain.

Analysis of different habitat factors in different types of wetlands in the study sites revealed that numerous habitat factors (vegetation, wetland area, water level, and human interference) influence waterbirds' distribution in different wetlands. Among these factors, vegetation and benthic organisms represent key factors influencing habitat choice of birds in wetlands [43]. Water levels influence food availability, and, in turn, waterbirds' distribution in different types of wetlands [19]. In addition, increasing human interference in the form of activities such as fishing and grazing [44] drive waterbirds to migrate to different habitat fragments. Therefore, rational management of habitat factors in artificial wetlands could minimize the adverse effects on wintering waterbirds of rapid conversion of natural lakeside wetlands in the middle and lower Yangtze River floodplain into artificial wetlands.

\section{Conclusions}

To facilitate the conservation of waterbird diversity in the middle and lower Yangtze River floodplain, first, lake land use and management methods should be diversified. Simultaneous draining and filling up of large areas of crab farms and aquaculture ponds would cause wintering waterbirds to encounter drastic changes in habitat factors and they would be unable to adapt. Secondly, comprehensive and strict conservation of shallow lake communities should be strengthened in the middle and lower Yangtze River floodplain. Certain natural wetland areas should be maintained, and the restoration of large areas of cultivated land into wetlands should be carried out to restore the integrity of wetland ecosystems. Similarly, water conservation facilities should be used to manage ecosystems as buffers for drastic changes in environmental factors within relatively short periods. Such activities would facilitate the maintenance of stable habitats for overwintering waterbirds. For example, maintaining a reasonable water level in lakes and maintaining specific areas of flooded paddy fields during winter could enable waterbirds to select the most suitable habitats. In addition, 
staggered drainage and filling up of artificial aquaculture ponds could provide suitable continuous foraging habitats for waterbirds. Therefore, understanding the characteristics of artificial wetland habitats and investigating the underlying mechanisms by which different patch habitats influence overwintering bird community distribution could facilitate the maintenance of overwintering waterbird community structures.

Author Contributions: Conceived and designed the experiments, L.Z.; funding acquisition, L.Z.; contributed the materials/analysis tools, L.Z.; liaised with reserve authorities and obtained province guidance and permission for the field work, L.Z.; performed the experiments, X.W.; participated in the field work, X.W. and J.C.; analyzed the data, X.W. and J.C.; wrote the paper, X.W. and J.C. All authors have read and agreed to the published version of the manuscript.

Funding: The study was supported by the National Natural Science Foundation of China (Grant No. 31472020).

Acknowledgments: In this study, a monocular (16/52x) and binoculars $(8 \times)$ were used to observe the species and numbers of waterbirds in the survey sites. When data was collected, our distance to birds was generally more than $500 \mathrm{~m}$. Our study data did not involve the hunting of any animals. Permission was obtained from the Anhui Anqing Yanjiang Lakes Provincial Nature Reserve.

Conflicts of Interest: The authors declare no conflict of interest. The funder had no role in the design of the study; in the collection, analyses, or interpretation of data; in the writing of the manuscript, or in the decision to publish the results.

\section{References}

1. Zhang, S.X.; Dong, Y.X.; Xia, F. Significance of waterbird monitoring in lake ecosystems. J. Lake Sci. 2011, 23, $155-162$.

2. Ramachandran, R.; Kumar, A.; Gopi, S.K.; Bhalla, R.S. Hunting or habitat? Drivers of waterbird abundance and community structure in agricultural wetlands of southern India. Ambio 2017, 46, 613-620. [CrossRef] [PubMed]

3. Sebastián-González, E.; Sánchez-Zapata, J.A.; Botella, F. Agricultural ponds as alternative habitat for waterbirds: Spatial and temporal patterns of abundance and management strategies. Eur. J. Wildl. Res. 2009, 56, 11-20. [CrossRef]

4. Zhao, J.X.; Liu, H.; Zhang, L.Q. Spatial Patterns for the Distribution of Winter Waterbirds in the Aquaculture Ponds of Chongming Dongtan, Shanghai. Zoo. Res. 2008, 29, 212-218. [CrossRef]

5. Chen, J.Y.; Zhou, L.Z.; Zhou, B. Seasonal dynamics of wintering waterbirds in two shallow lakes along Yangtze River in Anhui Province. Zoo. Res. 2011, 32, 540-548.

6. Zhou, B.; Zhou, L.Z.; Chen, J.Y. Diurnal time-activity budgets of wintering hooded cranes (Grus monacha) in Shengjin Lake, China. Waterbirds 2010, 33, 110-115. [CrossRef]

7. Zhao, F.T.; Zhou, L.Z.; Xu, W.B. Habitat utilization and resource partitioning of wintering hooded cranes and three goose species at Shengjin Lake. Chin. Birds 2013, 4, 281-290. [CrossRef]

8. Bellio, M.G.; Kingsford, R.; Kotagama, S.W. Natural versus artificial- wetlands and their waterbirds in Sri Lanka. Biol. Conserv. 2009, 142, 3076-3085. [CrossRef]

9. Chen, J.Y.; Zhou, L.Z. Guild structure of wintering waterbird assemblages in shallow lakes along Yangtze River in Anhui Province, China. Acta. Ecol. Sin. 2011, 31, 5323-5331.

10. Chen, B.; Cui, P.; Xu, H. Assessing the suitability of habitat for wintering Siberian Cranes (Leucogeranus leucogeranus) at different water levels in Poyang Lake area, China. Pol. J. Ecol. 2016, 64, 84-97. [CrossRef]

11. Holm, T.E.; Clausen, P. Effects of water level management on autumn staging waterbird and macrophyte diversity in three Danish coastal lagoons. Bio. Conserv. 2006, 15, 4399-4423. [CrossRef]

12. Tanalgo, K.C.; Pineda, J.A.; Agravante, M.E. Bird diversity and structure in different land-use types in lowland South-Central Mindanao, Philippines. Trop. Life Sci. Res. 2015, 26, 85-103. [PubMed]

13. White, C.L.; Main, M.B. Waterbird use of created wetlands in golf-course landscapes. Wildl. Soc. Bull. 2005, 33, 411-421. [CrossRef]

14. Schuh, M.H.; Guadagnin, D.L. Habitat and landscape factors associated with the nestedness of waterbird assemblages and wetland habitats in South Brazil. Austral Ecol. 2018, 43, 989-999. [CrossRef]

15. Stanton, R.L.; Morrissey, C.A.; Clark, R.G. Analysis of trends and agricultural drivers of farmland bird declines in North America: A review. Agric. Ecosyst. Environ. 2018, 254, 244-254. [CrossRef] 
16. Ma, Z.J.; Li, B.; Zhao, B. Are artificial wetlands good alternatives to natural wetlands for waterbirds?-A case study on Chongming Island, China. Bio. Conserv. 2004, 13, 333-350. [CrossRef]

17. MacGregor-Fors, I. Relation between habitat attributes and bird richness in a western Mexico suburb. Landsc. Urban Plan. 2007, 84, 92-98. [CrossRef]

18. Yu, C.X.; Yang, G.; Lu, Z. Habitat use by waterbirds in coastal wetlands during migratory seasons in Shankou Nature Reserve, Guangxi, South China. Oceanol. Lim. Sin. 2014, 45, 513-521.

19. An, A.; Cao, L.; Jia, Q.; Wang, X.; Zhu, Q.; Zhang, J.; Ye, X.; Gao, D. Changing abundance and distribution of the wintering Swan Goose Anser cygnoides in the middle and lower Yangtze River floodplain: An investigation combining a field survey with satellite telemetry. Sustainability 2019, 11, 1398. [CrossRef]

20. Bater, M.; Liwei, C.; Lei, C. Waterbird Survery of the Middle and Lower Yangtze River Floodplain in Late January and February 2004; China Forestry Publishing House: Hefei, China, 2004.

21. Aharon-Rotman, Y.; McEvoy, J.; Zheng, Z.J. Water level affects availability of optimal feeding habitats for threatened migratory waterbirds. Ecol. Evol. 2017, 7, 10440-10450. [CrossRef]

22. Rodríguez-Villafañe, C.; Bécares, E.; Fernández-Aláez, M. Waterfowl grazing effects on submerged macrophytes in a shallow Mediterranean lake. Aquat. Bot. 2007, 86, 25-29. [CrossRef]

23. Chen, X.; Li, B.L.; Scott, T.A. Spatial structure of multispecies distributions in southern California, USA. Biol. Conserv. 2005, 124, 169-175. [CrossRef]

24. Gill, F.; Donsker, D.; Rasmussen, P. IOC World Bird List (v10. 1). 2020. Available online: www.worldbirdnames.org (accessed on 2 August 2020).

25. Ma, K.P.; Liu, Y.M. Measurement method I for biological community diversity: Alpha diversity measurement method (the second half). Chi. Bio. 1994, 2, 231-239.

26. Liu, C.R.; Ma, K.P. Measurement of biotic community diversity VI. The statistical aspects of diversity measures. Bio. Science. 1998, 6, 229-239.

27. Zhao, P.; Yuan, X.; Tang, S.X. Species and habitat preference of waterbirds at the eastern end of Chongming Island (Shanghai) in Winter. Zoo. Res. 2003, 24, 387-391.

28. Liu, J.; Niu, J.Y.; Zou, Y.A. Changes in the waterbird community of the ecological restored wetlands in Pudong Dongtan, Shanghai. Resour. Environ. Yangtze. Basin. 2015, 24, $219-226$.

29. Smiley, P.C., Jr.; Maul, J.D.; Cooper, C.M. Avian community structure among restored riparian habitats in northwestern Mississippi. Agri. Eco. Environ. 2007, 122, 149-156. [CrossRef]

30. Yang, Y.X.; Bai, H.T.; Fu, W. Bird diversity and its correlation with the habitat structure in Dashanbao Black-necked Cranes Nature Reserve. Chin. J. Zoo. 2018, 37, 147-156.

31. Jin, X.; Ren, X.T.; Peng, H.B. Habitat use and factors affecting distribution of wintering waterbirds in the wetland restoration area at Chongming Dongtan. Chin. J. Zoo. 2013, 48, 686-692.

32. Connor, K.J.; Gabor, S. Breeding waterbird wetland habitat availability and response to water-level management in Saint John River floodplain wetlands, New Brunswick. Hydrobiologia 2006, 567, 169-181. [CrossRef]

33. Kaminski, R.W.; Baldassarre, G.A.; Pearse, A.T. Waterbird responses to hydrological management of wetlands reserve program habitats in New York. Wildl. Soc. Bull. 2006, 34, 921-926. [CrossRef]

34. Fang, W.; Chu, H.J.; Cheng, B.Y. Modeling waterbird diversity in irrigation ponds of Taoyuan, Taiwan using an artificial neural network approach. Paddy Water Environ. 2009, 7, 209-216. [CrossRef]

35. Hsu, C.H.; Chou, J.Y.; Fang, W.T. Habitat selection of wintering birds in farm ponds in Taoyuan, Taiwan. Animals 2019, 9, 113. [CrossRef]

36. Zhang, Y.; Xie, H.B.; Zeng, W.B. The waterfowl community structure and waterflowl habitat-selection analysis for four artificial wetlands type in spring in Chongming Dongtan, China. Chin. J. Zoo. 2014, 49, 490-504.

37. Nurqamareena, K.; Chong, Y.L.; Mohd-Azlan, J. A survey of understory birds at a rice field and a mixed dipterocarp forest in Kuching Sarawak. Malays. Appl. Biol. 2018, 47, 217-222.

38. Zheng, M.; Zhou, L.; Zhao, N. Effects of variation in food resources on foraging habitat use by wintering Hooded Cranes (Grus monacha). Avian Res. 2015, 6, 11. [CrossRef]

39. Perkins, A.J.; Maggs, H.E.; Wilson, J.D. Winter bird use of seed-rich habitats in agri-environment schemes. Agric. Ecos. Environ. 2008, 126, 189-194. [CrossRef]

40. Sandsten, H.; Klaassen, M. Swan foraging shapes spatial distribution of two submerged plants, favouring the preferred prey species. Oecologia 2008, 156, 569-576. [CrossRef] 
41. Zou, Y.A.; Zhang, P.Y.; Zhang, S.Q. Crucial sites and environmental variables for wintering migratory waterbird population distributions in the natural wetlands in East Dongting Lake, China. Sci. Total Environ. 2019, 655, 147-157. [CrossRef]

42. Golet, G.H.; Low, C.; Avery, S. Using ricelands to provide temporary shorebird habitat during migration. Ecol. Appl. 2018, 28, 409-426. [CrossRef]

43. Gatto, A.; Quintana, F.; Yorio, P. Feeding behavior and habitat use in a waterbird assemblage at a marine wetland in coastal Patagonia, Argentina. Waterbirds 2008, 31, 463-471. [CrossRef]

44. Kurosawa, R. Disturbance-induced bird diversity in early successional habitats in the humid temperate region of northern Japan. Ecol. Res. 2008, 24, 687-696. [CrossRef]

(C) 2020 by the authors. Licensee MDPI, Basel, Switzerland. This article is an open access article distributed under the terms and conditions of the Creative Commons Attribution (CC BY) license (http://creativecommons.org/licenses/by/4.0/). 